\title{
NanoEmulsion for Nanotechnology Size-Controlled Synthesis of Pd (II) Nanoparticles via NanoEmulsion Liquid Membrane
}

\author{
Said N EI*, Kassem AT, and Aly HF
}

Hot Labs, AtomicEnergy Authority, Egypt

\begin{abstract}
Palladium nanoparticles with low polydispersity were fabricated via emulsion globules of various sizes with same sauter mean diameter has been proposed for this purpose. In this paper, the important variables affecting sauter mean diameter of the emulsion drops, including injection method of emulsion, stirring speed, oil phase viscosity, composition of inner water phase and solute permeation rate are also systematically investigated of $\mathrm{HCl} /$ Co (III) dicarbolide/xylene/ $\mathrm{HCl}$ forming $\left(\mathrm{PdCl}_{4}\right)^{-2}$ in the presence of span $80 / 85$ as the surfactants. The particle size, ranging from 3.2 to $4.2 \mathrm{~nm}$, was optimized be controlled by variation of the surfactant, the agitation time and the concentrations. Nano emulsions were prepared using the spontaneous emulsification mechanism as non-equilibrium systems. XRS, SEM and surface area were used for analysis and the optimized coditions of nanopalladium was $2.5,1.1$ and 0.1 for $\mathrm{O} / \mathrm{S}$, glouble diameter and polydispersity respectively. The studies on optimization methods for nano-emulsion gloubles be a required.
\end{abstract}

Keywords: Emulsion liquid membrane; Globule size; Nano palladium; Spain80/85; Polydispersity

\section{Introduction}

Palladium is used in jewelry in dentistry $[1,2]$ and production of surgical [3] instruments. Palladium is also used to make professional transverse flutes [4]. The second biggest application of palladium in electronics is making the multilayer ceramic capacity [5]. Palladiums (and palladium-silver alloys) are used as electrodes in multi-layer ceramic capacitors; Palladium (sometimes alloyed with nickel) is used in connector plating's in consumer electronics. Hydrogen easily diffuses through heated palladium; thus, it provides a means of purifying the gas [6]. Membrane reactors with Pd membranes are therefore used for the production of high purity hydrogen. A large number of carbon-carbon bond forming reactions in organic chemistry are facilitated by catalysis with palladium compounds. The largest use of palladium today is in catalytic converters [7]. In addition palladium, when dispersed on conductive materials, proves to be excellent electro catalysts for oxidation of primary alcohols in alkaline media [8]. These recent applications have made that studies on optimization methods for nanoemulsion preparation of palladium be required. This work is focused on the most recent developments of nano-emulsions as final application products and on the optimization of their preparation. Nano emulsions consist of fine oil-in-water dispersions, having droplets covering the size range of $100-600 \mathrm{~nm}$. In the present work, nano-emulsions were prepared using the spontaneous emulsification mechanism which occurs when an organic phase and an aqueous phase are mixed. The organic phase is a homogeneous solution of oil, lipophilic surfactant and water-miscible solvent, the aqueous phase consists on hydrophilic surfactant and water. An experimental study of nano-emulsion process optimization based on the required size distribution was performed in relation with the type of oil, surfactant and the water-miscible solvent. The results showed that the composition of the initial organic phase was of great importance for the spontaneous emulsification process, and so for the physico-chemical properties of the obtained emulsions. First oil viscosity and HLB surfactants were changed, the most viscous oil gave the smallest droplets size $(16 \pm 2 \mathrm{~nm})$ HLB required for the resulting oil-in-water emulsion was superior to 8 . Second, the effect of water-solvent miscibility on the emulsification process was studied by decreasing xylene proportion in the organic phase. The solvent-xylene proportion leading to a fine nano-emulsion was fixed at $10 \%$ of membrane. This phase of emulsion optimization represents an important step in the process of nano size droplet by spontaneous emulsification. In the separation process using emulsion liquid membranes, the polydispersity affects mass transport of metal ions from the external phase to the internal phase because under steady operating conditions, drop size and size distribution are proportional to the interfacial area. The present study aims to assess the optimized conditions nano size of emulsion globules. An advancing reaction front model is considering. The work divided in two parts, first part the optimized conditions of preparation of palladium, and the second part is the suitable conditions for per traction of palladium. The modeling of transport of cations was achieved by advancing stripping model [9]. The carrier mediated transport from high salt content using TBP as membrane was done [10,11].

\section{Nanoemulsion}

The formation properties and applications of nano-emulsions are referred as mini emulsions, ultrafine emulsions, and submicron emulsions [12-15]. Nano-emulsion droplet sizes fall typically in the range of $20-200 \mathrm{~nm}$ and show narrow size distributions. The most publications on either oil-in-water (Oil/water) or water-in-oil (W/O) nano-emulsions report their formation by dispersion or high energy emulsification methods.

\section{Nano particles and Experimental design}

These materials are prepared for permeation metal ions followed by stripping to yield $\left(\mathrm{PdCl}_{4}\right)^{-2}$ in stripping phase to yield palladium

*Corresponding author: Said N El, Hot Labs, AtomicEnergy Authority, Egypt, Tel:202 01063699770; E-mail: neseem.abdel@yahoo.com

Received October 19, 2013; Accepted November 27, 2013; Published November 29, 2013

Citation: Said N El, Kassem AT, Aly HF (2013) NanoEmulsion for Nanotechnology Size-Controlled Synthesis of Pd (II) Nanoparticles via NanoEmulsion Liquid Membrane. J Membra Sci Technol 3: 125. doi:10.4172/2155-9589.1000125

Copyright: (c) 2013 SaidN El T, et al. This is an open-access article distributed under the terms of the Creative Commons Attribution License, which permits unrestricted use, distribution, and reproduction in any medium, provided the original author and source are credited. 
metal nanoparticle at the end of the process. The size of such particles depends on the number of metal ions initially loaded into the globules [16]. An orthogonal 24 factorial central composite experimental design with 6 star points $(I=1.68)$ and 6 replicates at the center point, all in duplicates, resulting in a total of 20 experiments were used to optimize the chosen key variables for the extraction of palladium. The experiments with different agitation speeds are 13000, 14000, 15000, 16000 and $17000 \mathrm{rpm}$ and $\mathrm{M} / \mathrm{E}$ ratio $0.1,0.2,0.3,0.4$ and $0.5(\% \mathrm{v} / \mathrm{v})$ and five different carrier concentration $0.01,0.05,0.1,0.15$ and $0.2 \mathrm{M}$ of Co (III) dicarbolide of employed simultaneously covering the spectrum of variables for the percentage extraction of palladium in the Central Composite Design. In order to describe the effects of agitation speed (X1), M/E ratio (X2) and carrier concentration (X3) on percentage of palladium extraction, batch experiments were conducted (Table1). Full factorial design matrix of screening experiments and mean droplet diameter measured (Table 2).

Experimental field for a design matrix: variables emulsion properties measured. For production of Pd nanoparticle by emulsion liquid membrane (ELM). The first step is the use of emulsion liquid membrane cell. The

\begin{tabular}{|c|c|c|c|c|c|}
\hline Run & \%span80/85 & O/S & $\begin{array}{l}\text { Addition } \\
\text { time (min) }\end{array}$ & $\begin{array}{c}\text { Agitation } \\
\text { rate (rpm) }\end{array}$ & $\begin{array}{c}\text { Droplet } \\
\text { diameter }(\mathrm{nm})\end{array}$ \\
\hline 1 & $\begin{array}{c}0.09 \\
0.1\end{array}$ & 1.0 & 1 & 14000 & 15.085 \\
\hline 2 & 0.1 & 1.0 & 1 & 14400 & $16 . .05$ \\
\hline 3 & 0.2 & 2.0 & 1 & 15000 & 20.0 .5 \\
\hline 4 & 0.3 & 2.0 & 2 & 16000 & 23.45 \\
\hline 5 & 0.4 & 2.0 & 2 & 16500 & 18.1 \\
\hline 6 & 0.8 & 2.0 & 2 & 17000 & 25.45 \\
\hline 7 & 1.5 & 2.5 & 3 & 17000 & 24.65 \\
\hline 8 & 2 & 2.5 & 3 & 16000 & 26.55 \\
\hline 9 & 2.5 & 3.0 & 4 & 14000 & 28.3 \\
\hline 10 & 2.8 & 3.0 & 5 & 14000 & 42.05 \\
\hline 11 & 3 & 3.5 & 5 & 16000 & 48.15 \\
\hline 12 & 3.2 & 3.5 & 5 & 16000 & 60.655 \\
\hline 13 & 4 & 2.5 & 6 & 16000 & 29.38 \\
\hline 14 & 4.5 & 2.5 & 6 & 15000 & 35.48 \\
\hline 15 & 5 & 3.5 & 6 & 14000 & 42.618 \\
\hline 16 & 5.5 & 3.5 & 6 & 14000 & 45.65 \\
\hline
\end{tabular}

Table 1: Full factorial design matrix of screening experiments and mean droplet diameter measured.

\begin{tabular}{|c|c|c|c|c|}
\hline Run & $\mathbf{S 8 0 / S 8 5}$ & O/S & Droplet diameter & Polydispersity \\
\hline 1 & 4.51 & 2 & 12.16 & 1.5312 \\
\hline 2 & 4.51 & 3 & 17.45 & 2.6576 \\
\hline 3 & 5.12 & 2 & 9.7 & 1.0296 \\
\hline 4 & 5.12 & 3 & 16.06 & 1.0296 \\
\hline 5 & 4.38 & 2.5 & 14.8 & 1.98 \\
\hline 6 & 5.25 & 2.5 & 14.16 & 1.1792 \\
\hline 7 & 4.82 & 1.79 & 7.6 & 0.8096 \\
\hline 8 & 4.82 & 3.21 & 14.82 & 1.2584 \\
\hline 9 & 4.82 & 2.5 & 11.1 & 1.1528 \\
\hline 10 & 48.2 & 2.50 & 11.1 & 0.100 \\
\hline 13 & 4 & 2.5 & 16 & 29.38 \\
\hline 14 & 4.5 & 2.5 & 14 & 35.48 \\
\hline 15 & 5 & 3.5 & 14 & 42.618 \\
\hline 16 & 5.5 & 3.5 & 14 & 45.65 \\
\hline
\end{tabular}

Table 2: Experimental field for a design matrix: variables emulsion properties measured. second step is using the $(\mathrm{F}+\mathrm{M})$. The third step is separation of Feed from membrane. The forth step is de-emulsioncation of membrane $(\mathrm{M})$ by electric charge using electric charge pistole. The fifth step is separation of strip from organic. The sixth step is heating and drying the stripping phase using a heater till $300 \mathrm{oC}$ to obtain Palladium nanoparticles and investigated by X-ray and SEM instruments (Figures 3-5). The treatment combinations and responses of two central composite designs that Powder XRD patterns of samples were recorded with a SHIMADZU XD-D1 Diffractometer using Ni-filtered CuKa radiation $\left(\mathrm{k}=1.5406 \mathrm{~A}^{\circ}\right)$ with the scan rate of $0.1 / \mathrm{s}$. TEM analysis was carried out using a Philips CM12 TEM (transmittance electron microscope), working at a $100 \mathrm{kV}$ accelerating voltage. Samples for TEM analysis were prepared by dispersing palladium, pd nanoparticles in ethanol followed by drop-casting on a copper grid (400 meshes). 9 - (Feed + Membrane), 10 - (Feed + Membrane), 11 - (Feed Membrane) (F + M), 12 - (Feed Membrane) (F + M), 12 - S, 13 - O (oxygen charge pistle), part-B.

\section{Experimental part for kinetic pertraction}

Co (III) dicarbolide/xylene, the surfactants of Liquid Emulsion Membrane SPAN 80 and 85 (sorbitol mono-and trioleate) and other chemicals were analytical grade. A turbine type impeller was used for preparation of the liquid membrane with organic; water volume ratio $\left(r_{1}\right.$ $=1)$ and at a mixing rate $(14000-16000) \mathrm{rpm}$ for $(5-10) \mathrm{min}$. Some emulsions remained stable for months. When breakage of emulsions was desired alcohols were used. The extraction of multiple (Water/Oil/ water) $\mathrm{W} / \mathrm{O} / \mathrm{W}$ emulsion was performed in a multi stages double-Jackets cell thermo stated temperature $25^{\circ} \mathrm{C}$ by stirring with magnetic bar $(50$ $\mathrm{x} 10 \mathrm{~mm}$ ) stirrer at (300 - 700) rpm usually with $50 \mathrm{ml}$ of outer (feed) solution. The extraction was followed by sample taking $(0.5-1.0 \mathrm{ml})$ from solution and measuring by the Atomic absorption spectroscopy type. Atomic absorption/Emission Spectrophotometer/210/VGP, Buck Scientific, USA was used for determination of palladium concentration. The $\mathrm{pH}$ values were measured using a $\mathrm{pH}$-meter of the type B-417 HANA Instrument hydrogen ion concentration in the solution. The deviations in the readings were in the range of \pm 0.02 at the laboratory temperature $25 \pm 2^{\circ} \mathrm{C}$ the cell used in pertraction of nano palladium metal using emulsion liquid membrane is shown. This design is repre $\neg$ sented by a second-order polynomial regression model (Equation 1), to generate contour plots

$$
\mathrm{Y}=\mathrm{b}_{0}+\mathrm{b}_{1} \mathrm{x}_{1}+\mathrm{b}_{2} \mathrm{x}_{2}+\mathrm{b}_{11} \mathrm{x}_{21}+\mathrm{b}_{22} \mathrm{x}_{22}+\mathrm{b}_{12} \mathrm{x}_{1} \mathrm{x}_{2}+\varepsilon \text {. (1) }
$$

\section{Results and Discussion}

Characteristics and properties of nano-emulsions, as nonequilibrium systems independent only on composition but also in the preparation method, although interest in nano-emulsions was developed since about 20 years ago, mainly for nanoparticle preparation, it is in the last years that direct applications of nano-emulsions in consumer products are being developed, mainly in pharmacy. These results were made for studies on optimization methods for nano-emulsion preparation is necessary [12].

\section{Preparation of nano particles from nano emulsion}

Palladium chloride ( $\mathrm{PdCl} 2)$ nano-particles with $\mathrm{Pd} / \mathrm{PdCl} 2=$ 65:35\% were prepared by an emulsion liquid membrane technique under mechanical agitation without the aid of any surface-active agent. SEM images of black particles are shown in (Figure 4 and 5). Aggregates of irregular shaped particles are observed and the size of Pd particles varies from 4 to $33 \mathrm{~nm}$. A nanoparticle also is observed in SEM image as shown in (Figure 1 and 5) before and after preparation of nanoparticles of palladium. Hence, it was difficult to calculate the particle size distribution from SEM images. The (Figure 3) is indexed 
to be corresponding to (112), (2020), (218), (309), (329) and (418) of $\mathrm{Pd}$ metal. Powder XRD pattern of Pd nanoparticles is shown in (Figure 2) the d-spacing corresponding to XRD lines are 1.986, 1.888, 1.299, 1.099 and $1.098 \mathrm{~A}^{\circ}$. These $\mathrm{d}$-spacing values correspond to (111), (200), (220), (311) and (222) planes [13-16]. Particle size analysis showed a narrow distribution of 25-120 nm range particles with a mean size of $60 \mathrm{~nm}$, thus, confirming their nano-structured nature. Nano-particles of palladium powders were prepared at a significantly low temperature. From the above optimization process different parameters were studied for preparation of nanoparticles and the different parameters were studied as in (Figures 1-3). XRD spectra of palladium nanoparticles (Figure 4 and 5) SEM image of palladium before and after using ELM at $20^{\circ} \mathrm{C}$ and $\mathrm{pH}=4$. One with $\mathrm{O} / \mathrm{S}$, oil/surfactant $(80 / 85)$ relation the optimization of three parameters as 3-D was shown in (Figure 6) (X1) is the agitation speed, $\mathrm{rpm}, \mathrm{M} / \mathrm{E}$ ratio $\%(\mathrm{v} / \mathrm{v})$ which is the volume of membrane/feed, (X2) and carrier concentration (X3) and the plotting of two dimensional contour plots (Figure 7).

Droplet size and polydispersity Emulsion droplet size and polydispersity (intensity based size distributions) were measured by photon correlation spectroscopy (PCS) using Malvern Zetasizer ZS at $25^{\circ} \mathrm{C}$. Samples were diluted with water for the measurements The crystallite size was calculated using the Debye-Scherrer formula, $\mathrm{D}=$ $0.9 \lambda / \beta$ where $\mathrm{D}$ is the particle size, $\lambda$ the wavelength of the $\mathrm{X}$-ray used, $\beta, \theta$ are the half-width of X-ray diffraction lines and half diffraction angle of $2 \theta$. The crystallite size was found to be between 30 and $8 \mathrm{~nm}$ template.

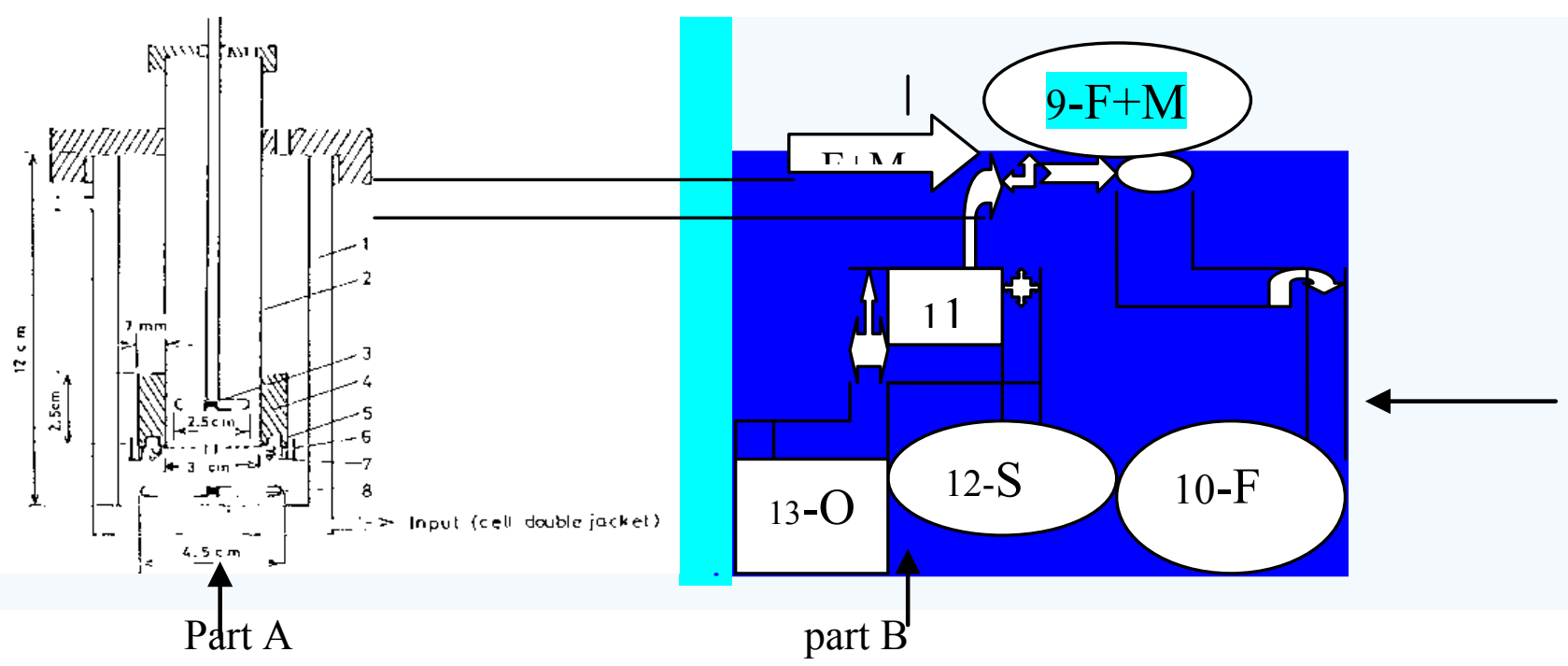

Figure 1: Scheme of pertraction apparatus for production of Pd nanoparticle by ELM: (1)double shield glass outer vessel, (2) Plexiglas inner tube, (3)Teflon cross stirring blade, (4) Teflon holder, (5) silicon rubber ring, (6) niobium holder, (7) titanium holder, (8) magnet,(9)-F+M(feed, membrane),(11)-electric charge pestol,(12-S),(13-O), (10-F)-solvent.

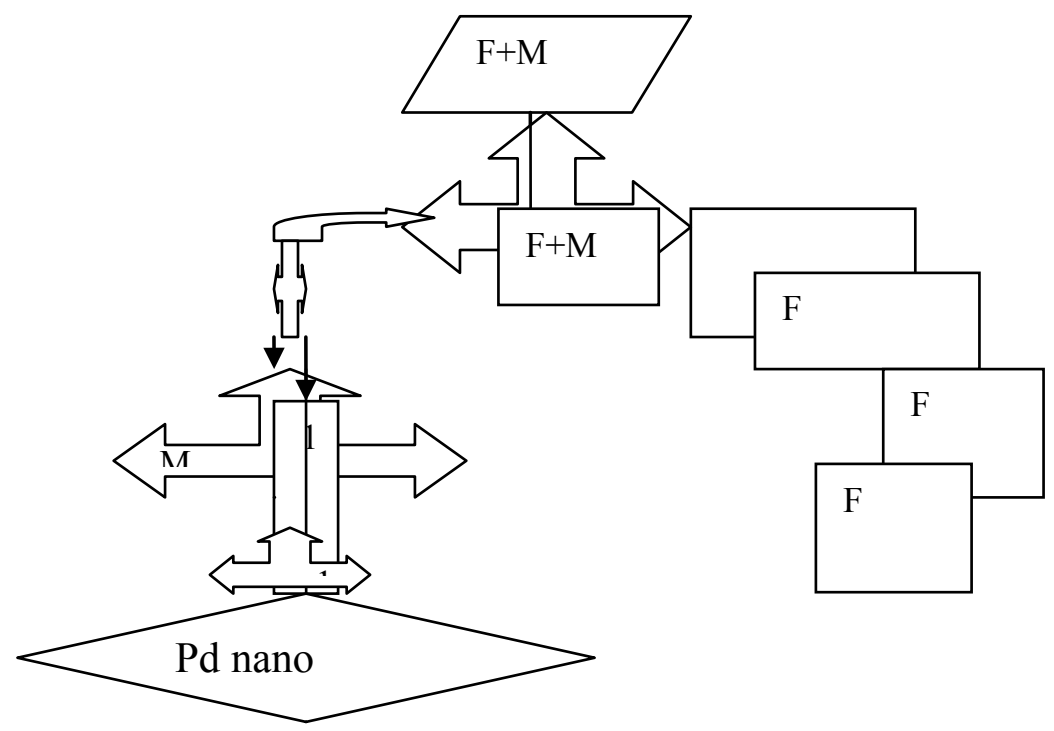

Figure 2: Flow chart for Cell design for production of Pd nanoparticle by ELM. 


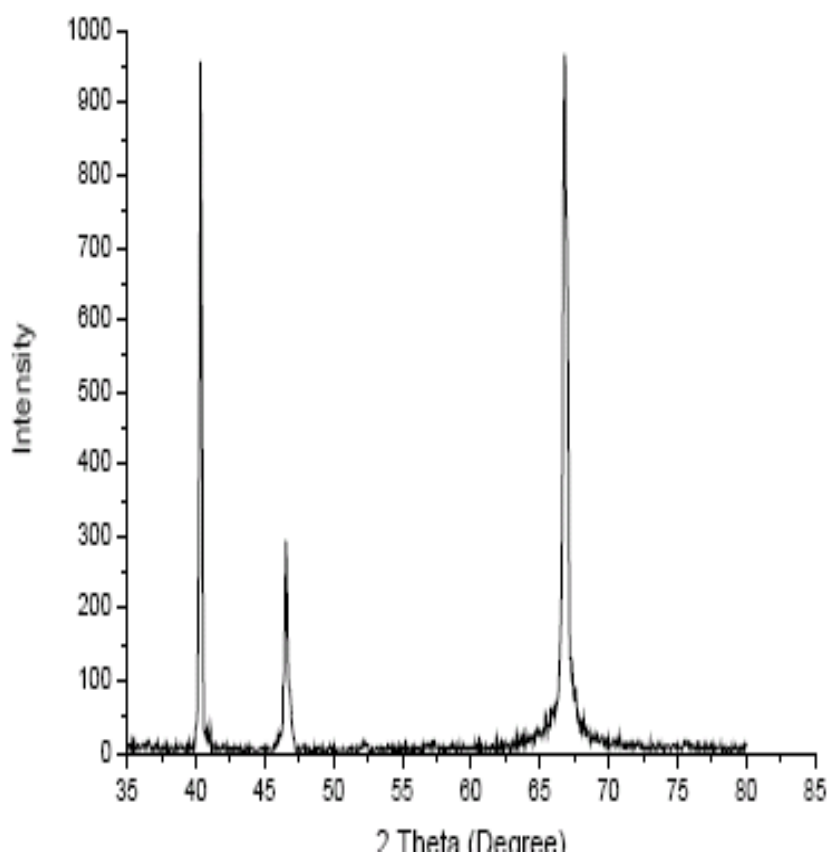

Figure 3: XRD spectra of palladium before Using ELM nano particles.

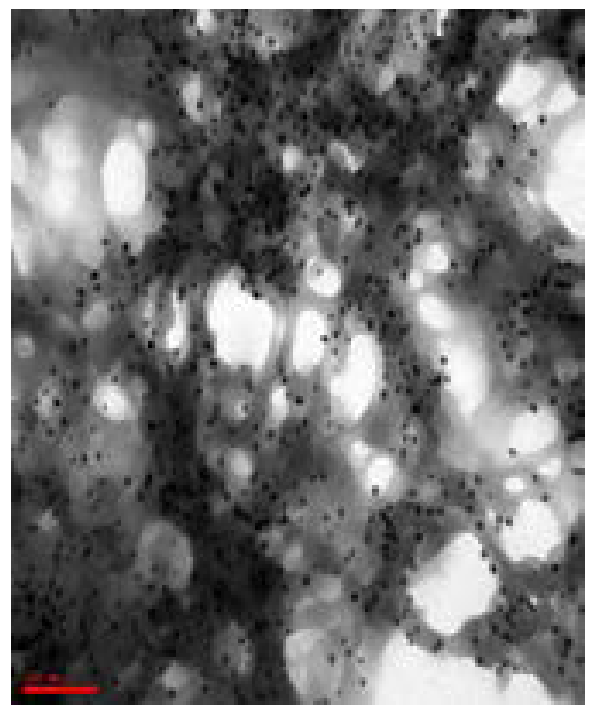

Figure 4: SEM image of palladium nanopartical25-120 $\mathrm{nm}$ range particles with a mean size of $60 \mathrm{~nm}$.

Each 3D plot represents the number of combinations of the three variables, showing the effects of agitation speed, $\mathrm{M} / \mathrm{E}$ ratio and their mutual interaction on extraction of palladium emulsion liquid membrane, ELM using Co (III) dicarbolide as carrier.

\section{Kinetic study}

At a constant interface area in double emulsion system and when the concentration of separated element in feed solution is much lower than the concentration of carrier in membrane and their chemical interaction does not change the concentration of carrier at interphase substantially, most of the results on membrane extraction (pertraction) can be approximated by a pseudo-first order kinetic law [11]

$$
\log \left(1-\frac{R}{R \infty}\right)=-\mathrm{Kt}
$$

Or

$$
\mathrm{R}=\mathrm{R}_{\infty}\left(1-\mathrm{e}^{-\mathrm{kt}}\right)
$$

Where $\mathrm{R}$ is the fraction yield of pertraction .

$\mathrm{K}$ is the rate of pertraction $\mathrm{min}^{-1}$.

\section{Influence of aqueous phase acidities}

Influence of the feed solution acidity from $\mathrm{pH}(1$ to 4$)$. Figure 8 dipicts the effect $\mathrm{pH}$ on the extraction of nano particle of Pd (II), it is found that as the $\mathrm{pH}$ increases the pertraction of palladium increases and the maximum yield of pertraction reached 0.98 at $\mathrm{pH}=4$.

\section{Effect of membrane phase}

Figure 9 Show the influence of membrane concentration from $(0.01 \mathrm{M}-0.06 \mathrm{M} \mathrm{HCl})$ on the pertraction of $\mathrm{Pd}^{+2}$, as the membrane increases, the extraction yield increases till 0.95 at $0.01 \mathrm{M}$.

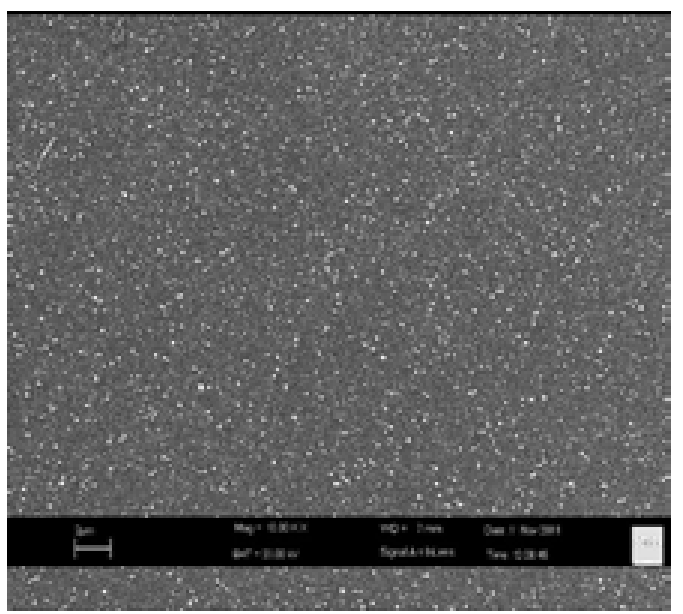

Figure 5: SEM image of Nano palladium afterusing Emulsion liquid membrane.

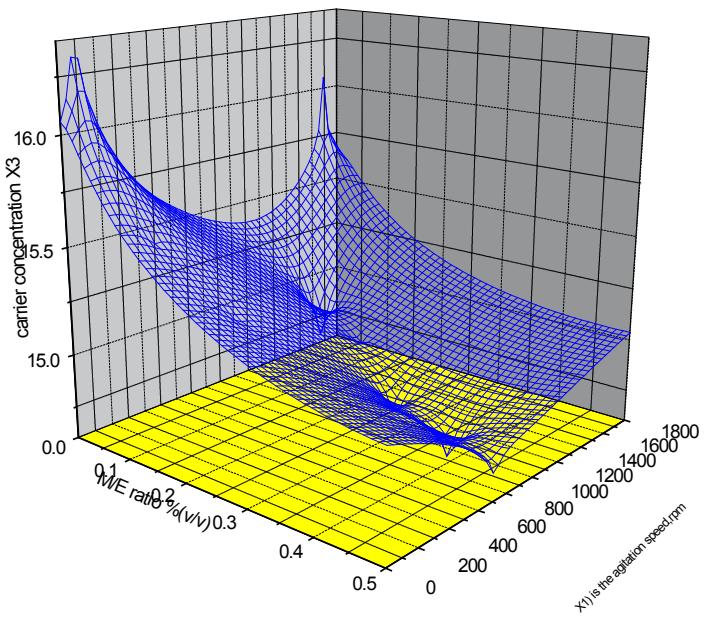

Figure 6: 3-D Optimization Plots. 


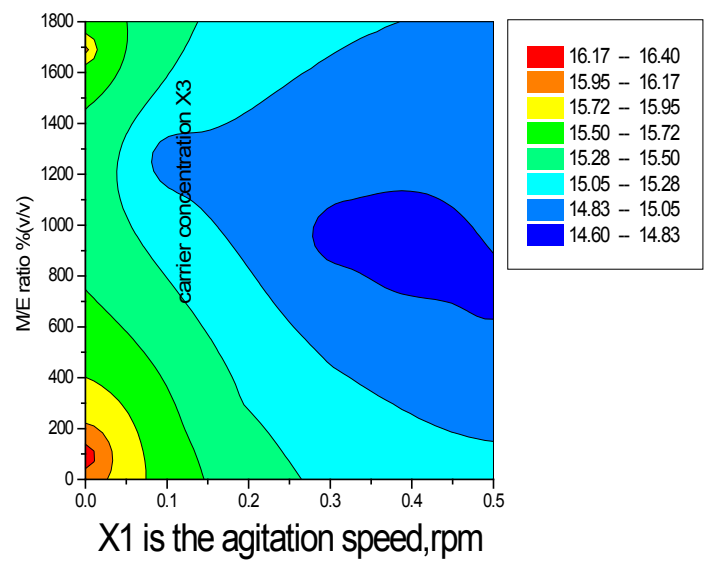

Figure 7: The contour plot.s of (X1), M/E ratio (X2) and $\mathrm{X} 3$ and carrie concentration, $\mathrm{M}$.

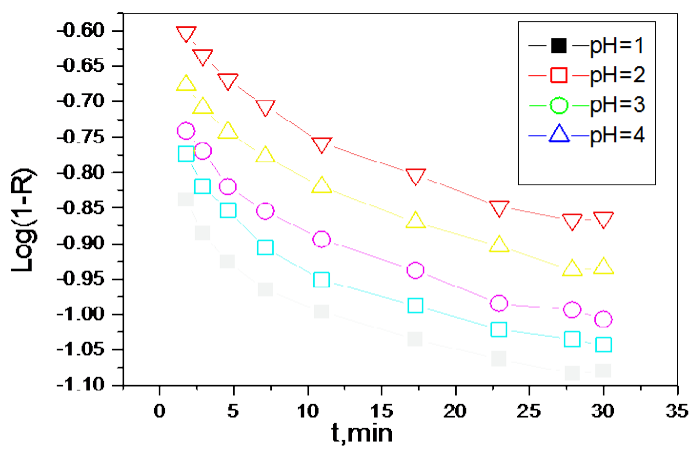

Figure 8: Effect of $\mathrm{pH}$ on pertraction of $\mathrm{pd}^{+2}$ with emulsion of $\mathrm{H}^{+}(\mathrm{B})_{2}$ in xylene, $\mathrm{F}=0.001 \mathrm{M} \mathrm{HCl}+0.01 \mathrm{NaCl}, 0.01 \mathrm{M}$ of $\mathrm{pd}^{+2,} \mathrm{M}=0.01 \mathrm{MH}^{+1}(\mathrm{~B})_{2}, 3 \%$ SPAN, $80 / 85$, $(3: 1), \mathrm{S}=0.03 \mathrm{M} \mathrm{HCl}$

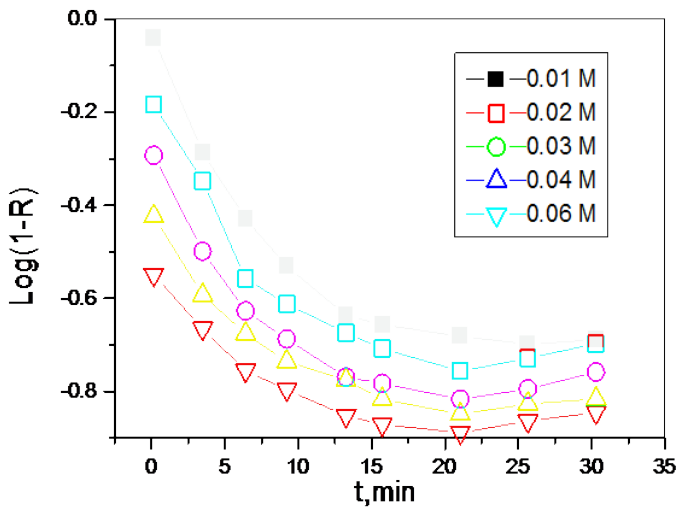

Figure 9: Effect of membrane phase conceniJation on pertraction of pcfwith errulsicms ofW'(B),.m xylene, $F=0.01 \mathrm{M} \mathrm{Ha}+() .01 \mathrm{M} \mathrm{Naa}, 0.01 \mathrm{M}$ of $\mathrm{pa}^{2}, \mathrm{M}=\mathrm{x} 0.1 \mathrm{M}$ $W^{\prime}(B), ., 3 \%$ SPAN,80/85(3:1) 5=\{)_03 M Ha.

\section{Effect of stripping phase}

Figure 10 Shows the influence of strip concentration from $(0.01 \mathrm{M}$ $-0.5 \mathrm{M} \mathrm{HCl})$ on the pertraction of Pd (II). It is interesting to note that the effects of changing strip concentration on the transport of Pd (II) achieve to obtain $99 \%$ of pertraction yield were different.

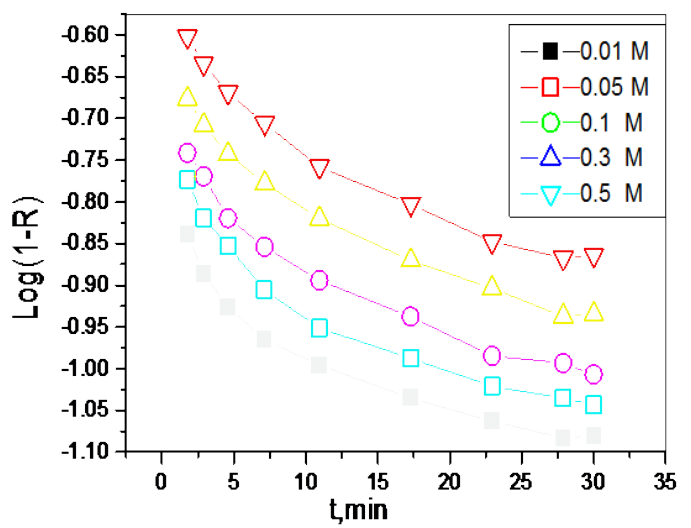

Figure 10: Effect of stJpg phase coocenlralion on pel1ractioo of pd2 wilh emulsions of $H^{\circ}(B)$ in xylene, $F .01 \mathrm{M} \mathrm{HCJ}+0.001 \mathrm{M} 2 \mathrm{NaC} 1,0.01 \mathrm{M}$ of pd.2, M. $1 \mathrm{M} \mathrm{H} \cdot(B), ., 3 \%$ SPAN, 80/85, (3:1), S=xM Ha.

\section{Conclusion}

The of preparation of palladium by $\mathrm{Co}$ (III) dicarbolide from aqueous feeding solution to yield nano particles of palladium in the globule of stripping phase was a chivied and can be studied via optimization at different surfactant concentration, the agitation speed and emulsification time to use nano particles of palladium for pharmaceutical industry. It is found that the emulsion stability was carried out by varying surfactant concentration, agitation speed and emulsification time. The optimum process conditions for the extraction of palladium $1500 \mathrm{rpm}$, $\mathrm{M} / \mathrm{E}$ ratio- $-0.75 \%(\mathrm{v} / \mathrm{v})$ and carrier concentration $5 \%(\mathrm{v} / \mathrm{v})$. In nano of ELM, palladium can be optimized through size control of the globule size nano emulsion for nanotechnology. A size-controlled synthesis of Palladium nanoparticles via nano emulsion liquid membrane, ELM, was succeeded. Criterion will depend on particular weight adjudged to either recovery yield, reactants cost and time of performance. There are maxima on neither partial global criterial functions, just local minimum (worst performance) should be avoided to make the process reasonable. A Nano particle size pertraction of palladium was optimized using ELM technique and the effect of different parameters such feeding, membrane and stripping phases were studied. The 3-D optimization and contour plot predict conditiones of preparation of nanoparticles of palladium.

\section{References}

1. Kristine HE, Gregory MM, Rauch S (2004) Environmental routes for platinum group elements to biological materials a review. J Science of the Total Environment: 21

2. Hesse, Rayner W (2007) Palladium. Jewelrymaking through history: an encyclopedia Greenwood Publishing Group J: 146

3. S Navaladian (2009) A Rapid Synthesis of Oriented Palladium Nanoparticles by UV Irradiation. J Nanoscale Research Letters: 02

4. Chakraborty M (2003) Effect of drop size distribution on mass transfer analysis of the extraction of nickel (II) by emulsion liquid membrane. Colloids and Surfaces A: Physicochemical and Engineering Aspects: 829.

5. Rajasimman M (2009) Optimization of process parameters for the extraction of chromium (VI) by emulsion liquid membrane using response surface methodology. J of Hazardousn Materials: 830.

6. Grochala W, Edwards PP (2004) Thermal Decomposition of the Non-Interstitial Hydrides for the Storage and Production of Hydrogen. J Chem Rev: 283.

7. Solans C, Izquierdo P, Nolla J, Azemar N, Garcia MJ, et al. (2005) Current Opinion in Colloid \& Interface Science 102. 
Citation: Said N El, Kassem AT, Aly HF (2013) NanoEmulsion for Nanotechnology Size-Controlled Synthesis of Pd (II) Nanoparticles via NanoEmulsion Liquid Membrane . J Membra Sci Technol 3: 125. doi:10.4172/2155-9589.1000125

8. JM Gutiérrez, C González, A Maestro, I Solè, CM Pey et.al (2008) Current Opinion in Colloida \& Interface Science. 245.

9. El-Said N (2003) Modeling of transport of Cs (137) by emulsion liquid membrane $(18 \mathrm{C} 6)$ in xylene Promoted by ephedrine hydrochloride in stripping phase. J of Membrane Science: 131.

10. Nowier $H$ (2000) Carrier-mediated transport of toxic elements through liquid membranes. J of Membrane Science: 830.

11. Said N (1992) Emulsion liquid membrane extraction of fission products promoted by polyvalent and organic acids. $\mathrm{J}$ of Radioanalytical and Nuclear Chemistry Articles: 11.

12. Navaladian S, Viswanathan B, Varadarajan TK, Viswanath RP (2009) A Rapid Synthesis of Oriented Palladium Nanoparticles by UV Irradiation's. Nanoscale Res Lett: 181.
13. Nishi T, Takeichi A, Azuma H, Suzuki N, Hioki T, et al. (2010) Fabrication of Palladium Nanoparticles by Laser Ablation in Liquid. JLMN-J of Laser Micro/ Nanoengineering: 3 .

14. Pey CM (2006) Optimization of nano-emulsions prepared by low-energy emulsification methods at constant temperature using a factorial design study. $\mathrm{J}$ of Colloids and Surfaces A: Physicochemical and Engineering Aspects: 1005.

15. Sathishkumara M, Snehaa K, Kwaka IS, Maoa J, Tripathy SJ et al. (2009) Phyto-crystallization of palladium through reduction process using Cinnamomzeylanicum bark extracts. J of Hazardous Materials: 171.

16. Alexander P, Majewski, Schallon A, Jérôme V, Freitag R, et al. (2012) DualResponsive Magnetic Core-Shell Nanoparticles for Nonviral Gene Delivery and Cell Separation. J of Biomacromolecules: 857. 